\title{
Screening for mild cognitive impairment in people with obesity: a systematic review
}

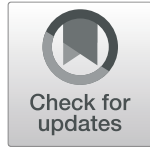

Nimantha Karunathilaka ${ }^{1 *}$ and Sarath Rathnayake ${ }^{2}$

\begin{abstract}
Objective: Recent evidence demonstrates that obesity is associated with developing cognitive impairment. However, evidence related to the assessment of mild cognitive impairment (MCl) in people with obesity is limited. Therefore, this systematic review aimed to examine evidence concerning the screening of $\mathrm{MCl}$ in people with obesity from the general population.

Method: We conducted a systematic search of CINHAL, EMBASE, MEDLINE, PsycINFO and PubMed electronic databases for observational studies to assess $\mathrm{MCl}$ in people with obesity from the general population. PRISMA guideline was followed. The articles published from January 2011 to July 2021 were included.

Results: Database search found 3104 sources. After the screening process, two articles from China and Egypt were included. The main age groups assessed were middle-aged adulthood and older adulthood. There were no studies undertaken in young adults or across the life span. Obesity was assessed by body mass index. MCl was assessed by cognitive screening tools; Mini-mental State Examination and Addenbrooke's Cognitive Examination. The prevalence of $\mathrm{MCl}$ in people with obesity was $18.5 \%$ and $42.9 \%$ in Chinese and Egyptian studies, respectively. Only one study supported a positive association between $\mathrm{MCl}$ and obesity.

Conclusions: Limited studies were found on screening $\mathrm{MCl}$ in people with obesity in the general population. The available evidence was not adequate to explain the overall prevalence, possible associations, and the best tool for assessing $\mathrm{MCl}$ in people with obesity. Expanding screening studies for $\mathrm{MCl}$ in people with obesity in the general population is essential.
\end{abstract}

Keywords: General population, Mild cognitive impairment, Obesity, Screening

\section{Introduction}

Obesity is a complex and multifactorial but preventable disease [1], and around one-third of the world population is considered overweight or obese [2]. Obesity is defined as abnormal and excessive fat accumulation that presents a risk to health $[1,2]$. Regardless of age, gender, geography or socioeconomic status, there is an increasing trend of obesity $[3,4]$. Obesity leads to many noncommunicable diseases, for example, diabetes, cardiovascular diseases, and cancer $[2,5]$. Additionally, evidence

\footnotetext{
* Correspondence: nimantha.karunathilaka@kdu.ac.lk

${ }^{1}$ Department of Nursing and Midwifery, Faculty of Allied Health Sciences, General Sir John Kotelawala Defence University, Ratmalana, Sri Lanka

Full list of author information is available at the end of the article
}

indicates that obesity is associated with the development of cognitive impairment and has a higher potential for developing dementia in the mid and later life of individuals [6-8]. Several pathophysiological mechanisms explain the influence of obesity in cognitive impairment. Obesity reduces neural integrity, including atrophy of grey and white matter, shrinking the hippocampus, and reducing prefrontal cortex volume, contributing to cognitive impairment $[7,9]$. Furthermore, central and systemic inflammation, the over-activation of microglia and astrocytes, and blood-brain barrier dysfunction also play a significant role in cognitive impairment among people with obesity [9-12].

(c) The Author(s). 2021 Open Access This article is licensed under a Creative Commons Attribution 4.0 International License, which permits use, sharing, adaptation, distribution and reproduction in any medium or format, as long as you give appropriate credit to the original author(s) and the source, provide a link to the Creative Commons licence, and indicate if changes were made. The images or other third party material in this article are included in the article's Creative Commons licence, unless indicated otherwise in a credit line to the material. If material is not included in the article's Creative Commons licence and your intended use is not permitted by statutory regulation or exceeds the permitted use, you will need to obtain permission directly from the copyright holder. To view a copy of this licence, visit http://creativecommons.org/licenses/by/4.0/ The Creative Commons Public Domain Dedication waiver (http://creativecommons.org/publicdomain/zero/1.0/) applies to the data made available in this article, unless otherwise stated in a credit line to the data. 
Age-related cognitive decline is a normal biological process in humans [13] and is independently associated after adjusting the major neuropathological factors in later life [14]. Additionally, mild cognitive impairment (MCI) is the stage of cognition between normal cognition and dementia and is the first sign of the alteration of cognition [15-17]. Usually, MCI can be reversed to normal cognition, while dementia is the permanent damage of neural activities $[15,16]$. Therefore, early identification of MCI is essential to plan strategies to promote health and sminimise the risk of developing dementia.

Obesity is classified as sgeneralised and central obesity. sGeneralised obesity is assessed by body mass index (BMI), and central obesity is assessed by waistto-hip ratio (WHR) [18]. Obesity, including sgeneralised or central obesity or both, has been positively associated with cognitive impairment in young [8] and middle adulthood [19-23]. However, Vidyanti et al. [24] and Pedditizi et al. [25] reported that older age is less frequently associated with cognitive impairment in people with obesity. Although a number of studies are available to assess cognitive impairment in people with obesity, there is little attention to the examination of MCI in people with obesity from the general population. Additionally, the majority of studies have been conducted among obese people with specific disease conditions such as diabetes [26], cardiovascular disease [27], obstructive sleep apnea [28] and HIV infection [29]. Furthermore, some studies do not support the identification of MCI as they have focused on the identification of overall impairment of cognitive functions [30-32]. Furthermore, there was a lack of evidence in selecting the best MCI screening tool for the disease-specific cohort as well as various study designs [26-29]. Therefore, the present study aimed to critically review the available literature on screening of $\mathrm{MCI}$ in people with obesity from the general population.

\section{Methods}

A systematic review was conducted to gather the available evidence for screening of MCI among people with obesity in the general population. The main research question was formulated using the PICO/PIO method, where "P" stood for the study population i.e., people with obesity in the general population, including a high body mass index (sgeneralised obesity) or a high waistto-hip ratio (central or abdominal obesity) and excessive adiposity. "I" stood for intervention, which was the screening of $\mathrm{MCI}$, while outcome "O" was referred to as identifying $\mathrm{MCI}$ of people with obesity. Consequently, the following review questions were addressed in this systematic review:
1. What is the prevalence of $\mathrm{MCI}$ in people with obesity in the general population?

2. What are the cognitive assessment tools that can be used for screening mild cognitive impairment among people with obesity?

We searched five electronic databases: CINHAL, EMBASE, MEDLINE, PsycINFO and PubMed. The search terms were scategorised into two conceptual areas: "Body Mass Index" OR "Waist-to hip-ratio" OR "Waist-to-hip ratio" OR Adiposity [MeSH] OR Obesity $[\mathrm{MeSH}]$ AND "Mild cognitive impairment" OR "Mild cognitive dysfunction" [MeSH] OR "Mild mental deterioration" OR "Mild cognitive decline" OR "Neurocognitive disorder" $[\mathrm{MeSH}]$. Keyword searches were performed on title, abstract and keywords using Boolean operators. The Preferred Reporting Items for Systematic Reviews and Meta-Analyses (PRISMA) guidelines were followed in the screening process [33]. Moreover, the reference lists of selected full-text articles were screened further to find any additional relevant articles, and none were found.

The inclusion criteria for the review were studies that included human subjects aged 18 and over and peerreviewed journal articles published in English from January 2011 to June 2021. Moreover, MCI should be screened in the people with obesity from the general population or community. Additionally, observational studies were included for this review, including cohort studies, case-control studies, and cross-sectional studies. We excluded studies that focused on screening obesity in people who were already diagnosed with MCI, cognitive impairment, and any other psychological disorders. Articles that did not state local or internationally accepted cut off values to define obesity (sgeneralised or central), and the subjects who have been diagnosed with metabolic syndrome were also excluded. Moreover, experimental studies, case reports, case series, review articles, editorials, and commentaries were excluded.

The literature search was combined with mesh terms, specific terms, and keywords. There were 3104 articles, including 502 from PubMed, 1876 from EMBASE, 483 from Medline, 112 from CINHAL and, 131 from PsycINFO. After removing 555 duplicates, 2549 articles were selected for titles and abstracts screening. Both authors (NK \& SR) screened $10 \%$ of sources (255 articles) for titles and abstracts based on the given inclusion and exclusion criteria, and the consensus was achieved. Then, NK continued the title and abstract screening. Based on the title and abstract review, 2505 articles that did not meet the study inclusion criteria were excluded. A total of 44 articles were included in the full-text review. Initially, two authors reviewed the content of the full-text articles. The average initial kappa value was 
0.645. Discrepancies were discussed, and a consensus was achieved. Finally, two articles that satisfied the inclusion criteria were included for the final analysis (Fig. 1).

Information about all included studies was tabulated under the following: author, year, location, the aim of the study, study design, participant age, sample size, obesity assessment method, data collection tools, and main outcomes. Furthermore, extracted information was rearranged based on the type of obesity assessment and age categories to evaluate the better patterns of cognitive screening tools. The methodological quality of the studies was assessed by Jonna Briggs Institute (JBI) critical appraisal tools [34]. Meta-analysis was not possible because the selected two studies can not be meaningfully pooled, and their results were not sufficiently similar, increasing the heterogenicity of the pooled results [35]. Furthermore, the protocol of this systematic review was registered in the PROSPERO website (CRD42021260547).

\section{Results}

\section{Study characteristics}

One study was a cross-sectional survey conducted in China [36], while the other was a case-control study conducted in Egypt [37]. The age groups were above 45 years to below 55 years [37] and ages over 60 to 100 years [36]. The sample size in the Chinese study was 3242 [36]. In the Egyptian study, 161 obese people participated as cases while 61 healthy people participated as the control group [37] (Table 1).

\section{Screening tools for obesity and $\mathrm{MCl}$}

In both studies, sgeneralised obesity has been assessed through BMI $[36,37]$. The Chinese study is used the Asia Pacific cut off value to scategorised BMI into underweight, normal weight, overweight, and obesity [36, 38]. Egyptian study [37] has recruited obese people, and obesity is scategorised into obesity grades I, II and III: $30<$ BMI $>34.99$ (Grade I), 35<BMI $>39.99$ (Grade II), and BMI $>40$ (Grade III), respectively [39] (Table 1).

MCI has been assessed through the accepted cut-off values of Mini-Mental State Examination (MMSE) [36] and Addenbrooke's Cognitive Examination (ACE III) [37] (Table 1). MMSE consists of orientation, memory, attention, language, and visuospatial subdomains [40], while ACE consists of attention, memory, fluency, and language sub-domains [37]. The

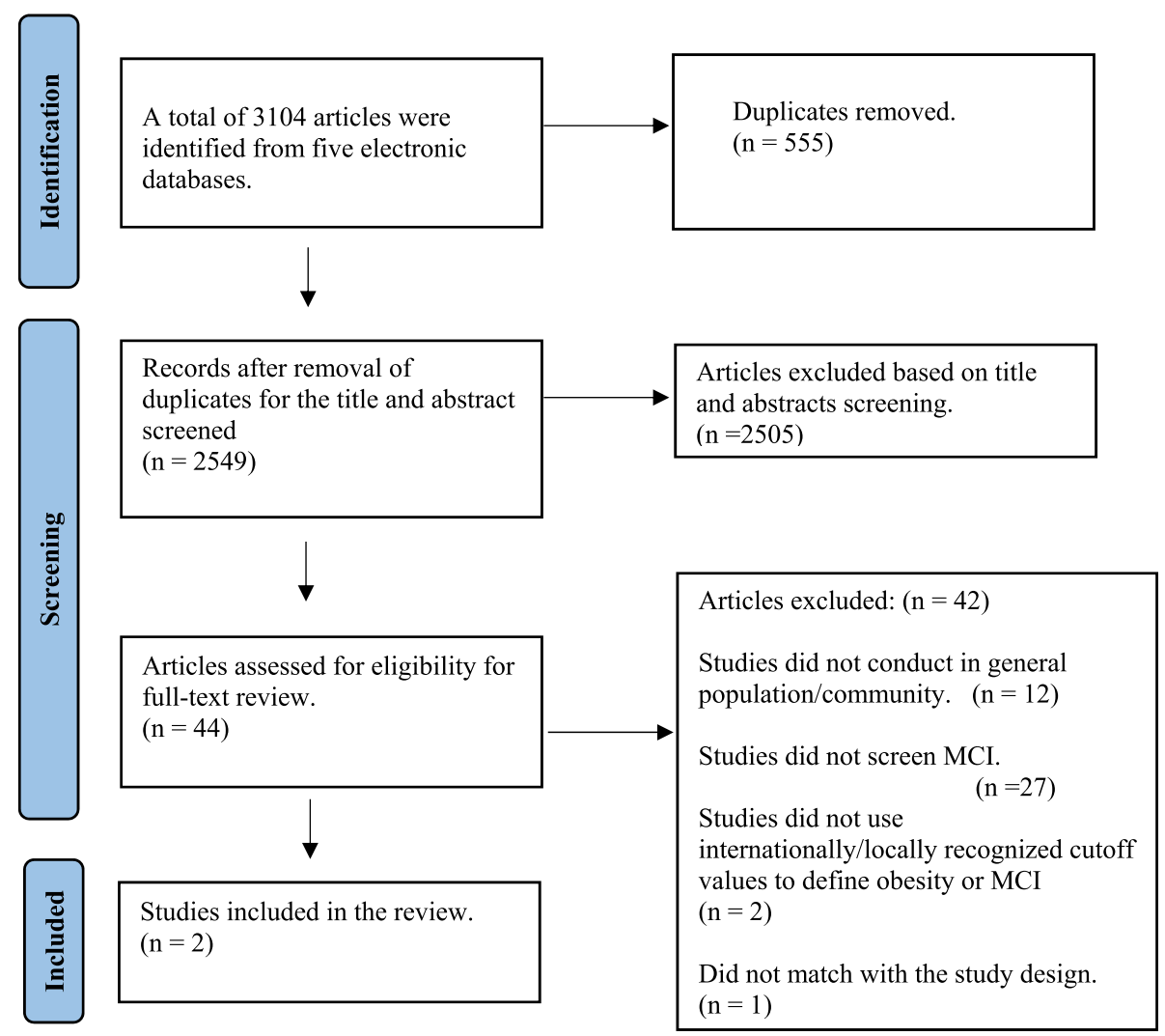

Fig. 1 Flow chart of study selection; Adapted from Page et al., [33] 
Table.1 Articles included in Systematic Review

\begin{tabular}{|c|c|c|c|c|c|c|c|}
\hline $\begin{array}{l}\text { Authors, } \\
\text { Year, } \\
\text { country }\end{array}$ & Aim of the study & $\begin{array}{l}\text { Study } \\
\text { Design }\end{array}$ & $\begin{array}{l}\text { Participants' } \\
\text { Age (in } \\
\text { years) }\end{array}$ & $\begin{array}{l}\text { Sample } \\
\text { Size }\end{array}$ & $\begin{array}{l}\text { Obesity } \\
\text { Assessment }\end{array}$ & $\begin{array}{l}\text { Cognitive } \\
\text { Screening } \\
\text { Tool }\end{array}$ & Major Findings \\
\hline $\begin{array}{l}\text { Yuan } \\
\text { et al., } \\
\text { [36] } \\
\text { China }\end{array}$ & $\begin{array}{l}\text { To investigate } \\
\text { gender and age as } \\
\text { moderators in the } \\
\text { association } \\
\text { between } \\
\text { BMl and mild } \\
\text { cognitive } \\
\text { impairment }(\mathrm{MCl}) \\
\text { among rural older } \\
\text { adults }\end{array}$ & $\begin{array}{l}\text { Cross- } \\
\text { sectional }\end{array}$ & $\begin{array}{l}\text { Aged } 60 \text { and } \\
\text { above } \\
\text { (Range from } \\
60 \text { to } 100 \text { ) } \\
\text { Age } \\
\text { scategorised } \\
\text { into } \\
\text { Below } 75 \\
\text { and above } \\
75 .\end{array}$ & $n=3242$ & $\begin{array}{l}\text { BMI } \\
\text { [sCategorised into underweight } \\
\text { (low BMI), normal weight } \\
\text { (normal BMI), overweight } \\
\text { (elevated BMI) and obese (high } \\
\text { BMI)] }\end{array}$ & $\begin{array}{l}\text { MMSE } \\
\text { (30 Items; } \\
\text { Chinese } \\
\text { Version) }\end{array}$ & $\begin{array}{l}\text { Below } 75 \text { years (Both men and } \\
\text { women) } \\
\text { There was no significant } \\
\text { difference in } \mathrm{MCl} \text { among } \\
\text { overweight and obese categories } \\
\text { when compared to normal BMI. } \\
\text { ( } p>0.05 \text { ) } \\
\text { Above } 75 \text { years. } \\
\text { Older men } \\
\text { Compared to nomal BMl } \\
\text { category, Overweight category } \\
\text { had higher risk of } \mathrm{MCl} \text { (aOR = } \\
2.32,95 \% \text { Cl: } 1.17-4.61 ; p<0.05 \text { ) } \\
\text { Older women } \\
\mathrm{BMI} \text { (overweight and Obesity) vs. } \\
\mathrm{MCl}-\mathrm{NS}\end{array}$ \\
\hline $\begin{array}{l}\text { Salama } \\
\text { et al., } \\
{[37]} \\
\text { Egypt }\end{array}$ & $\begin{array}{l}\text { To assess } \mathrm{MCl} \\
\text { prevalence and its } \\
\text { relation with } \\
\text { lifestyle } \\
\text { risk factors among } \\
\text { obese adults }\end{array}$ & $\begin{array}{l}\text { Case- } \\
\text { control }\end{array}$ & $\begin{array}{l}\text { Mean age } \\
\text { case (Obese) } \\
-52.1 \pm 5 \\
\text { Mean age } \\
\text { control } \\
\text { (Healthy) - } \\
51.3 \pm 6\end{array}$ & $\begin{array}{l}\text { Case } \\
\text { (Obesity) } \\
n=161 \\
\text { Control } \\
\text { (Healthy) } \\
n=69\end{array}$ & $\begin{array}{l}\text { BMI } \\
\text { Obesity Gr. I (BMI <35) } \\
\text { Obesity Gr. II (BMI 35-39.9) } \\
\text { Obesity Gr. III (BMI>40) }\end{array}$ & $\begin{array}{l}\text { ACE } \\
\text { (Version III) }\end{array}$ & $\begin{array}{l}\text { MCI was assessed between } \\
\text { Obesity categories (I, II and III) } \\
\text { and control (healthy adults) } \\
\text { MCI between Grade I and } \\
\text { Control (OR - } 5.5,95 \% \text { Cl: } 2.2- \\
13.5 ; p<0.001) \\
\text { MCI between Grade II and } \\
\text { Control (OR - } 6.8,95 \% \text { Cl: } 2.7- \\
16.9 ; p<0.001) \\
\text { MCI between Grade III and } \\
\text { Control (OR - } 4.8,95 \% \text { Cl: } 1.8- \\
12.5 ; p<0.001)\end{array}$ \\
\hline
\end{tabular}

Chinese study has a different cut-off value for screening MCI in MMSE based on participant's education level (MMSE cut-off <17 for illiteracy; MMSE cut-off $<20$ for up to primary education and, MMSE cut-off $<24$ for higher than primary education) [41]. In the Egyptian study, the cut-off value for screening MCI has been calculated based on the mean score of ACE III in healthy adults. The mean score of ACE III is 83. The cut-off value for screening MCI has been set below the mean score [42] (Table 1).

\section{Prevalence of $\mathrm{MCl}$ and its relationship with obesity}

Yuan et al. [36] reported that the prevalence of MCI was $18.5 \%$. Furthermore, only older men (age over 75 years) who had elevated BMI had a higher risk of MCI compared to normal BMI $(\mathrm{p}<0.05)$. There was no significant association between elevated/higher BMI and MCI ( $p>0.05$ ) in older men (age range from 60 to 75 yrs.) and women (age over 60 yrs.) [36] (Table 1). Salama et al., [37] revealed that the prevalence of MCI was $42.9 \%$ among people with obesity (cases). Furthermore, MCI was varied among Grade I, II, III, and the control group as $42.2 \%, 47.2 \%, 38.6 \%$, and $11.6 \%$, respectively [37]. MCI score was significantly different in Grade I, II, and
III categories when compared to the control $(p<0.001)$ [37] (Table 1).

\section{Discussion}

This systematic review aimed to evaluate the observational studies that screened MCI in people with obesity in the general population. We found that limited studies were available in the literature on assessing $\mathrm{MCI}$ in people with obesity in the general population. Our screening process identified that most of the studies were conducted among patients diagnosed MCI [43-45], cognitive impairment and dementia cohorts [46-48] and other disease specific populations, for example, diabetes, cardiovascular disease, obstructive sleep apnea and HIV infection [26-29]. Since only two studies examined MCI in people with obesity in the general population, metaanalysis was not meaningful as it was pooled in a single cross-sectional and case-control study, which increases the heterogenicity of the pooled results [35]. Furthermore, Mueller et al. [49] stated that there was scanty methodological guidance to perform systematic reviews and meta-analyses of observational studies. Therefore, it is difficult to make a precise conclusion on the prevalence of MCI, the relationship between MCI and obesity, and the best screening tools to screen MCI in obese 
people. Consequently, expanding studies to examine MCI in people with obesity in the general population is essential.

In the present review, the prevalence of $\mathrm{MCI}$ among people with obesity in the general population was $18.5 \%$ (cross-sectional) and $42.9 \%$ (case-control) in Chinese and Egyptian studies. However, Moretti et al., [50] and Lara et al., [51] stated that the prevalence of MCI in the general population in Italy and Span was around $6.0 \%$ and 9.6. Therefore, it is suggested that the prevalence of MCI is higher among people with obesity [36, 37] than the prevalence of MCI in the general population [50, 51]. We further found that a study in China reported the prevalence of MCI among people with obesity in the general population as $21.8 \%$ [52]. Additionally, stroke [50], depressive symptoms [50] or depression [51, 53], sleep disturbances [51], history of head injury [53], and lower educational status [53] are also potential associated factors for MCI in the general population. Consequently, early screening of $\mathrm{MCI}$ among people with obesity in the general population would be beneficial to mitigate further deterioration of cognitive function that leads to dementia in later life.

In line with the recent studies [24, 25], this study revealed that cognitive impairment was less frequently associated with older age. The present review supported that there was no relationship between MCI and older women (age over 60 years) and men (age below 75) with obesity. However, in middle adulthood, cognitive impairment among people with obesity was inconsistent. While the majority of studies revealed that there was a significant relationship between obesity and cognitive impairment $[20,21,28,51,52,54]$, only a few studies state that there was no such relationship [19, 22, 23]. However, the present review supports a significant relationship between MCI and obesity (Grade I, II, and III) during middle adulthood $(\mathrm{p}<0.05)$ [37]. Although there was no study among people with obesity within the age group of young adulthood, two studies conducted in the USA [8] and Iran [50] stated that there was a significant association between obesity and cognitive impairment. However, all these studies were conducted in the predefined?? population or disease-specific population and also did not state the cut-off value for mild, moderate, and severe cognitive impairment [53, 55-57].

Obesity is mainly assessed through sgeneralised and central obesity. Generalised obesity can be assessed through BMI and central obesity can be assessed by WHR [20, 21, 23]. In addition, fat mass, body fat percentage, and lipid accumulation products (LAP) are also used in estimating the level of obesity $[52,58]$. Although in the present review, BMI was the only used obesity screening anthropometric parameter, few studies suggested that WHR and LAP were more reliable anthropometric parameters than BMI, particularly in cognitive function screening $[52,58]$.

The studies included in the present review used MMSE and ACE III as the cognitive assessment tool. However, there are several cognitive screening tools available to screen cognition that cover various neuropsychological domains of cognition such as attention, memory, language, executive function, and orientation [40]. In studies that screened for cognition, MMSE [54, 59], Montreal Cognitive Assessment (MoCA) [19, 52], and Neuropsychological Batteries [8, 28, 58] have been used. The use of a combination of cognitive assessment tools help to discover different neuropsychological domains [40], and it provides a broader understanding of the occurrence of MCI in people with obesity. Furthermore, it will help to identify the best tool for screening MCI in people with obesity.

\section{Conclusions}

Although there was no adequate evidence to estimate the overall effect between MCI and obesity, the available findings in this systematic review support that the prevalence of MCI among people with obesity from the general population is higher. Furthermore, there is a higher potential to observe $\mathrm{MCI}$ in obese people compared to normal-weight people. Therefore, early identification of MCI in people with obesity is essential to diminish further deterioration of cognitive function and expand studies for MCI of people with obesity in the general population.

Furthermore, the following suggestions would be important for future studies: using a cognitive screening tool that can screen $\mathrm{MCI}$, incorporate numerous anthropometric parameters to screen obesity rather than limiting to a single anthropometric parameter and, perform subgroup analysis by possible age groups such as young, middle adulthood, older adulthood.

\section{Abbreviations \\ ACE III: Addenbrooke's Cognitive Examination; BMI: Body Mass Index; JBI: Jonna Briggs Institute; LAP: Lipid Accumulation Products; MMSE: Mini- Mental State Examination; MCI: Mild Cognitive Impairment; MoCA: Montreal Cognitive Assessment; PRISMA: The Preferred Reporting Items for Systematic Reviews and Meta-Analyses; WHR: Waist-to-Hip Ratio}

\section{Acknowledgements}

We acknowledged all authors of selected studies for their contribution to the field of obesity.

\section{Authors' contributions}

Conception and design: NK and SR. Acquisition of data and interpretation of data: NK (First reviewer) and SR (Second reviewer). Manuscript preparation and the first draft of the manuscript: NK. Critical review and editing of the manuscript: SR. Both authors have read and approved the final manuscript.

\section{Funding}

This research did not receive any specific grant from funding agencies in the public, commercial, or not-for-profit sectors. 


\section{Availability of data and materials}

Data sharing is not applicable to this article as no datasets were generated or analysed during the current study.

\section{Declarations}

\section{Ethics approval and consent to participate}

Not necessary.

\section{Consent for publication}

Not applicable.

\section{Competing interests}

There is no conflict of interest to be declared including the financial or personal relationship of any organisation.

\section{Author details}

'Department of Nursing and Midwifery, Faculty of Allied Health Sciences, General Sir John Kotelawala Defence University, Ratmalana, Sri Lanka. ${ }^{2}$ Department of Nursing, Faculty of Allied Health Sciences, University of Peradeniya, Peradeniya, Sri Lanka.

Received: 12 August 2021 Accepted: 5 November 2021

Published online: 17 November 2021

\section{References}

1. Hruby A, Hu FB. The Epidemiology of Obesity: A Big Picture. Pharmacoeconomics. 2015;33(7):673-89.

2. Chooi YC, Ding C, Magkos F. The epidemiology of obesity. Metabolism. 2019;92:6-10.

3. Cho NH, Shaw JE, Karuranga S, Huang Y, da Rocha Fernandes JD, Ohlrogge AW, et al. IDF Diabetes Atlas: Global estimates of diabetes prevalence for 2017 and projections for 2045. Diabetes Res Clin Pract. 2018;138:271-81.

4. Singh GM, Danaei G, Farzadfar F, Stevens GA, Woodward M, Wormser D, et al. The age-specific quantitative effects of metabolic risk factors on cardiovascular diseases and diabetes: a pooled analysis. PLoS One. 2013;8(7): e65174.

5. Lauby-Secretan B, Scoccianti C, Loomis D, Grosse Y, Bianchini F, Straif K, et al. Body Fatness and Cancer--Viewpoint of the IARC Working Group. N Engl J Med. 2016;375(8):794-8.

6. Kandimalla R, Thirumala V, Reddy PH. Is Alzheimer's disease a Type 3 Diabetes? A critical appraisal. Biochim Biophys Acta Mol Basis Dis. 2017; 1863(5):1078-89.

7. Dye L, Boyle NB, Champ C, Lawton C. The relationship between obesity and cognitive health and decline. Proc Nutr Soc. 2017;76(4):443-54.

8. Hovens IB, Dalenberg JR, Small DM. A Brief Neuropsychological Battery for Measuring Cognitive Functions Associated with Obesity. Obesity (Silver Spring, Md). 2019;27(12):1988-96.

9. Nguyen JC, Killcross AS, Jenkins TA. Obesity and cognitive decline: role of inflammation and vascular changes. Front Neurosci. 2014;8:375

10. Gustafson DR, Karlsson C, Skoog I, Rosengren L, Lissner L, Blennow K. Midlife adiposity factors relate to blood-brain barrier integrity in late life. J Intern Med. 2007;262(6):643-50.

11. Koyama A, O'Brien J, Weuve J, Blacker D, Metti AL, Yaffe K. The role of peripheral inflammatory markers in dementia and Alzheimer's disease: a meta-analysis. J Gerontol A Biol Sci Med Sci. 2013;68(4):433-40.

12. Miller AA, Spencer SJ. Obesity and neuroinflammation: a pathway to cognitive impairment. Brain Behav Immun. 2014:42:10-21.

13. Buckley R, Pascual-Leone A. Age-Related Cognitive Decline Is Indicative of Neuropathology. Ann Neurol. 2020;87(6):813-5.

14. Wilson RS, Wang T, Yu L, Bennett DA, Boyle PA. Normative Cognitive Decline in Old Age. Ann Neurol. 2020;87(6):816-29.

15. Tangalos EG, Petersen RC. Mild Cognitive Impairment in Geriatrics. Clin Geriatr Med. 2018;34(4):563-89.

16. Etgen $T$, Sander D, Bickel H, Forstl H. Mild cognitive impairment and dementia: the importance of modifiable risk factors. Dtsch Arztebl Int. 2011; 108(44):743-50.

17. Farias ST, Mungas D, Reed BR, Harvey D. Progression of Mild Cognitive Impairment to Dementia in Clinic- vs Community-Based Cohorts. Arch Neurol. 2009;66:1151-7.
18. Han TS, Sattar N, Lean M. Assessment of obesity and its clinical implications. BMJ. 2006:333:695-8.

19. Fan R, Zhao L, Ding BJ, Xiao R, Ma WW. The association of blood nonesterified fatty acid, saturated fatty acids, and polyunsaturated fatty acids levels with mild cognitive impairment in Chinese population aged 35-64 years: a cross-sectional study. Nutr Neurosci. 2021;24(2):148-60.

20. Fu J, Liu Q, Du Y, Zhu Y, Sun C, Lin H, et al. Age- and Sex-Specific Prevalence and Modifiable Risk Factors of Mild Cognitive Impairment Among Older Adults in China: A Population-Based Observational Study. Front Aging Neurosci. 2020;12:578742

21. Feng T, Feng Z, Jiang L, Yu Q, Liu K. Associations of health behaviors, food preferences, and obesity patterns with the incidence of mild cognitive impairment in the middle-aged and elderly population: An 18-year cohort study. J Affect Disord. 2020;275:180-6.

22. Li $Y$, Shang $S$, Fei $Y$, Chen $C$, Jiang $Y$, Dang $L$, et al. Interactive relations of type 2 diabetes and abdominal obesity to cognitive impairment: a crosssectional study in rural area of Xi'an in China. J Diabetes Complications. 2018;32(1):48-55.

23. Deckers K, Van Boxtel MPJ, Verhey FRJ, Köhler S. Obesity and Cognitive Decline in Adults: effect of Methodological Choices and Confounding by Age in a Longitudinal Study. J Nutr Health Aging. 2017;21(5):546-53.

24. Vidyanti AN, Hardhantyo M, Wiratama BS, Prodjohardjono A, Hu C-J. Obesity Is Less Frequently Associated with Cognitive Impairment in Elderly Individuals: A Cross-Sectional Study in Yogyakarta, Indonesia. Nutrients. 2020;12(2):367.

25. Pedditzi E, Peters $\mathrm{R}$, Beckett $\mathrm{N}$. The risk of overweight/obesity in mid-life and late life for the development of dementia: a systematic review and meta-analysis of longitudinal studies. Age Ageing. 2016;45(1):14-21.

26. Liu ZQ, Zhang MX, Wang J, Ding N. Analysis of correlation between the mild cognitive impairment $(\mathrm{MCl})$ and level of adiponectin in elderly patients with type 2 diabetes mellitus (T2DM). Eur Rev Med Pharmacol Sci. 2021; 21(23):5471-7.

27. Joo SH, Yun SH, Kang DW, Hahn CT, Lim HK, Lee CU. Body Mass Index in Mild Cognitive Impairment According to Age, Sex, Cognitive Intervention, and Hypertension and Risk of Progression to Alzheimer's Disease. Front Psychiatry. 2018;9:142.

28. Shen YC, Kung SC, Chang ET, Hong YL, Wang LY. The impact of obesity in cognitive and memory dysfunction in obstructive sleep apnea syndrome. Int J Obes (Lond). 2019;43(2):355-61.

29. Sattler FR, He J, Letendre S, Wilson C, Sanders C, Heaton R, et al. Abdominal obesity contributes to neurocognitive impairment in HIV-infected patients with increased inflammation and immune activation. JAIDS J Acquir Immune Defic Syndr. 2015;68(3):281-8,

30. Talaei M, Feng L, Barrenetxea J, Yuan J-M, Pan A, Koh W-P, Adiposity. Weight Change, and Risk of Cognitive Impairment: The Singapore Chinese Health Study. J Alzheimer's Dis. 2020;74(1):319-29.

31. Seo YK, Won CW, Soh Y. Associations between body composition and cognitive function in an elderly Korean population: A cohort-based crosssectional study. Medicine. 2021;100(9):e25027.

32. Zhang T, Yan R, Chen Q, Ying X, Zhai Y, Li F, et al. Body mass index, waistto-hip ratio and cognitive function among Chinese elderly: a cross-sectional study. BMJ Open. 2018;8(10):e022055.

33. Page MJ, McKenzie JE, Bossuyt PM, Boutron I, Hoffmann TC, Mulrow CD, et al. The PRISMA 2020 statement: an updated guideline for reporting systematic reviews. BMJ. 2021;372:n71.

34. Moola S, Munn Z, Tufanaru C, Aromataris E, Sears K, Sfetcu R, et al. Chapter 7: Systematic reviews of etiology and risk. In: Aromataris E, Munn Z, editors., et al., JBI Manual for Evidence Synthesis. 2020.

35. McKenzie JE, Brennan SE, Ryan RE, Thomson HJ, Johnston RV. Chapter 9 : Summarizing study characteristics and preparing for synthesis. In: Cochrane. 2021.

36. Yuan $Y$, Li J, Zhang N, Fu P, Jing Z, Yu C, et al. Body mass index and mild cognitive impairment among rural older adults in China: the moderating roles of gender and age. BMC Psychiatry. 2021;21(1):54.

37. Salama II, Abdelrahman AH, Salama SI, Abdellatif GA, Rabah TM, Saleh RM, et al. Obesity and predictors affecting the occurrence of mild cognitive impairment. Res J Pharmaceutical Biol Chemical Sci. 2018;9(1):748-56.

38. Zhou B. Predictive values of body mass index and waist circumference for risk factors of certain related diseases in Chinese adults--study on optimal cut-off points of body mass index and waist circumference in Chinese adults. Biomed Environ Sci. 2002;15:83-9. 
39. Borrell LN, Samuel L. Body mass index categories and mortality risk in US adults: the effect of overweight and obesity on advancing death. Am J Public Health. 2014;104(3):512-9.

40. Tsoi KK, Chan JY, Hirai HW, Wong SY, Kwok TC. Cognitive Tests to Detect Dementia: A Systematic Review and Meta-analysis. JAMA Intern Med. 2015 175(9):1450-8.

41. Wu L, He Y, Jiang B, Liu M, Wang J, Yang S, et al. The association between the prevalence, treatment and control of hypertension and the risk of mild cognitive impairment in an elderly urban population in China. Hypertens Res. 2016;39(5):367-75.

42. Jak AJ, Bondi MW, Delano-Wood L, Wierenga C, Corey-Bloom J, Salmon DP, et al. Quantification of five neuropsychological approaches to defining mild cognitive impairment. Am J Geriatr Psychiatry. 2009;17(5):368-75.

43. Bae S, Shimada H, Park H, Lee S, Makizako H, Doi T, et al. Association between body composition parameters and risk of mild cognitive impairment in older Japanese adults. Geriatr Gerontol Int. 2017;17(11):2053-9.

44. Wang F, Zhao M, Han Z, Li D, Zhang S, Zhang Y, et al. Association of body mass index with amnestic and non-amnestic mild cognitive impairment risk in elderly. BMC Psychiatry. 2017;17(1):334.

45. Cova I, Clerici F, Maggiore L, Pomati S, Cucumo V, Ghiretti R, et al. Body mass index predicts progression of mild cognitive impairment to dementia. Dementia Geriatr Cognitive Disord. 2016;41(3-4):172-80.

46. Aiken-Morgan AT, Capuano AW, Arvanitakis Z, Barnes LL. Changes in Body Mass Index Are Related to Faster Cognitive Decline Among African American Older Adults. J Am Geriatr Soc. 2020;68(11):2662-7.

47. Concha-Cisternas Y, Lanuza F, Waddell H, Sillars A, Leiva AM, Troncoso C, et al. Association between adiposity levels and cognitive impairment in the Chilean older adult population. J Nutr Sci. 2019;8:e33.

48. Kim G, Choi S, Lyu J. Body mass index and trajectories of cognitive decline among older Korean adults. Aging Mental Health. 2020;24(5):758-64.

49. Mueller M, D'Addario M, Egger M, Cevallos M, Dekkers O, Mugglin C, et al. Methods to systematically review and meta-analyse observational studies: a systematic scoping review of recommendations. BMC Med Res Methodol. 2018;18(1):44.

50. Moretti F, De Ronchi D, Palmer K, Forlani C, Morini V, Ferrari B, et al. Prevalence and characteristics of mild cognitive impairment in the general population. Data from an Italian population-based study: the Faenza Project. Aging Mental Health. 2013;17(3):267-75.

51. Lara E, Koyanagi A, Olaya B, Lobo A, Miret M, Tyrovolas S, et al. Mild cognitive impairment in a Spanish representative sample: prevalence and associated factors. Int J Geriatr Psychiatry. 2016;31 (8):858-67.

52. Yu ZW, Li X, Wang Y, Fu YH, Gao XY. Association between Lipid Accumulation Product and Mild Cognitive Impairment in Patients with Type 2 Diabetes. J Alzheimer's Disease. 2020;77(1):367-74.

53. Derrig H, Lavrencic LM, Broe GA, Draper B, Cumming RG, Garvey G, et al. Mild cognitive impairment in Aboriginal Australians. Alzheimers Dement (N Y). 2020;6(1):e12054.

54. Bates KA, Sohrabi HR, Rainey-Smith SR, Weinborn M, Bucks RS, Rodrigues M, et al. Serum high-density lipoprotein is associated with better cognitive function in a cross-sectional study of aging women. Int J Neurosci. 2017;127(3):243-52.

55. Al Hazzouri AZ, Stone KL, Haan MN, Yaffe K. Leptin, mild cognitive impairment, and dementia among elderly women. J Gerontol A Biol Sci Med Sci. 2013;68(2):175-80.

56. Zhou Y, Flaherty JH, Huang C-Q, Lu Z-C, Dong B-R. Association between body mass index and cognitive function among Chinese nonagenarians/ centenarians. Dement Geriatr Cogn Disord. 2011;30(6):517-24.

57. Lavagnino L, Arnone D, Cao B, Soares JC, Selvaraj S. Inhibitory control in obesity and binge eating disorder: A systematic review and meta-analysis of neurocognitive and neuroimaging studies. Neurosci Biobehav Rev. 2016;68: 714-26.

58. Zhang Z, Zhang B, Wang X, Zhang X, Yang QX, Qing Z, et al. Olfactory Dysfunction Mediates Adiposity in Cognitive Impairment of Type 2 Diabetes: Insights From Clinical and Functional Neuroimaging Studies. Diabetes care. 2019;42(7):1274-83.

59. Owji M, Ashraf-Ganjouei A, Sahraian MA, Bidadian M, Ghadiri F, Naser Moghadasi A. The relationship between cognitive function and body mass index in multiple sclerosis patients. Mult Scler Relat Disord. 2019;32:37-40.

\section{Publisher's Note}

Springer Nature remains neutral with regard to jurisdictional claims in published maps and institutional affiliations.

Ready to submit your research? Choose BMC and benefit from:

- fast, convenient online submission

- thorough peer review by experienced researchers in your field

- rapid publication on acceptance

- support for research data, including large and complex data types

- gold Open Access which fosters wider collaboration and increased citations

- maximum visibility for your research: over $100 \mathrm{M}$ website views per year

At BMC, research is always in progress.

Learn more biomedcentral.com/submissions 